\title{
Pain, And Mental Health Features Before and During COVID-19 Pandemic Social Isolation in Brazil
}

\author{
Anelise Sonza ${ }^{1 *}$, Danúbia da Cunha de Sá Caputo ${ }^{2,3}$, José Alexandre Bachur ${ }^{4}$, Maria das Graças \\ Rodrigues de Araújo $^{5}$, Karen Valadares Trippo ${ }^{6}$, Dirceu Ribeiro Nogueira da Gama7, Daniel \\ Lago Borges ${ }^{8}$, Vanessa Amaral Mendonça ${ }^{9}$ and Mario Bernardo-Filho ${ }^{2}$
}

${ }^{1}$ Programa de Pós-Graduação em Ciências do Movimento Humano and Programa de Pós-Graduação em Fisioterapia, Centro de Ciências da Saúde e do Esporte, Universidade do Estado de Santa Catarina, R. Pascoal Simone, 358, Florianópolis, SC, Brazil

${ }^{2}$ Laboratório de Vibrações Mecânicas e Práticas Integrativas, Policlínica Piquet Carneiro, Instituto de Biologia Roberto Alcântara Gomes, Universidade do Estado do Rio de Janeiro, RJ, Brazil

${ }^{3}$ Faculdade Bezerra de Araújo, Rio de Janeiro, RJ, Brazil

${ }^{4}$ Universidade de Franca, Franca, SP, Brazil

${ }^{5}$ Universidade Federal de Pernambuco, PE, Brazil

${ }^{6}$ Universidade Federal da Bahia, BA, Brazil

${ }^{7}$ Universidade do Estado do Rio de Janeiro, RJ, Brazil

${ }^{8}$ Hospital Universitário da Universidade Federal do Maranhão, São Luís, MA, Brazil

${ }^{9}$ Laboratório de Inflamação e Metabolismo (LIM), CIPq Saúde, Universidade Federal dos Vales do Jequitinhonha e Mucuri (UFVJM), Diamantina, MG, Brazil

*Corresponding author: Anelise Sonza, Programa de Pós-Graduação em Ciências do Movimento Humano and Programa de PósGraduação em Fisioterapia, Centro de Ciências da Saúde e do Esporte, Universidade do Estado de Santa Catarina, R. Pascoal Simone, 358, Florianópolis, SC, Brasil

\section{ARTICLE INFO}

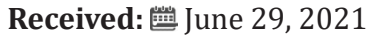

Published: 幽 July 23, 2021

Citation: Anelise Sonza, Danúbia da Cunha de Sá Caputo, José Alexandre Bachur, Maria das Graças Rodrigues de Araújo, Karen Valadares Trippo, et al., Pain, And Mental Health Features Before and During COVID-19 Pandemic Social Isolation in Brazil. Biomed J Sci \& Tech Res 37(3)-2021. BJSTR. MS.ID.006003.

Keywords: COVID-19; Pain; Stress; Anxiety; SARS-CoV-2; Quality of Life; Pandemic; Social Isolation

Abbreviations: SI: Social Isolation; HUPE: Hospital Universitário Pedro Ernesto; SE: Southeast; NE: Northeast

\section{ABSTRACT}

Background: The COVID-19 pandemic and social isolation measure has influenced the behavior and health of worldwide populations. The goal of this study was to investigate features related to pain, and mental health impact due to COVID-19 social isolation before and during the outbreak in Brazil and its mains macro-regions, which have climates, cultures, and economic differences.

Methods: This is an observational cross-sectional study through an online, validated, self-administered questionnaire (PEF-COVID19). The Brazilian general population, age $\geq 18$ years was invited to participate from 21th April until May 3rd 2020. T-test for independent samples and Chi-square tests were used to compare Brazil and different macro-regions ( $\mathrm{S}$, southern; SE southeastern; and NE, northeastern regions), before and during the pandemic, $\mathrm{p}<0.05$.

Results: A total of 1,977 participants filled the survey and 1,848 were included. Eighty percent of the included participants were in social isolation. In general, the self-related pain before and during the COVID-19 pandemic, mainly in the head and neck area increased in the SE region during the pandemic and the highest levels of self-related anxiety and stress (8-10) increased significantly in a similar way between the 3 mains macro-regions ( $\sim 10 \%$ to $34 \%$ and $\sim 14$ to $30 \%$, respectively).

Conclusions: The COVID-19 pandemic strongly influenced the levels of anxiety and stress increased in Brazil and its main macro-regions. The increase in pain mainly influenced the inhabitants of SE region. These results can be used to create measures, as home-based exercise programs, to avoid the harm of sedentary behaviors and mental health impact during and after the pandemic. 


\section{Introduction}

The necessity of being confined at home as a consequence of the outbreak of COVID-19 caused great involvement and concerns worldwide, changing drastically people daily life and quality of life [1], the economy and the nations' health systems, especially during the first wave of the pandemic. As a consequence of the Social Isolation (SI), a negative impact in the general health due to sedentary behaviors [2-6], pain [6,7] and lead to psychological conditions, such as anxiety and stress $[6,8,9]$ would be possibly expected. The study of SI impact has been investigated on pain conditions and mental health. A longitudinal study about SI in people seeking treatment for pain management investigated the SI interference on pain and provided evidence that individuals with higher levels of SI status presented greater impact on pain levels and decreased physical function [10]. Another study investigated whether SI predicts the clinical outcomes of disability, anxiety, depression and pain in people with low back pain [11].

Emotional support, to participate in social activities, and satisfaction are inherent to human beings [10] and negative social experiences can induce profound effect on our emotional wellbeing [12]; loneliness on a daily basis, shows an up regulation of pro-inflammatory response genes, which may contribute to the risk of inflammatory diseases in individuals who experience chronically high levels of subjective SI [13]. The degree of SI can induce a higher or lower prevalence of physical or mental health problems [12]. Considering that the first wave of COVID-19 caused great public concern, because the population experienced the fear of the unknown, the fear of death and the amount of daily information about the pandemic "numbers", the aim of this study was to use the validated questionnaire "Physical exercise level before and during social isolation" (PEF-COVID19) [14], to identify in Brazil and its mains macro-regions, the changes in the level of pain and psychological impact as stress and anxiety during the first wave of COVID-19 outbreak. Our hypothesis was that COVID-19 lockdown will result in major levels of self-related pain, anxiety and stress.

\section{Materials And Methods}

A self-administered questionnaire delivered through the e-mail and social media was conducted in this observational crosssectional study. The data collection happened in Brazil from $21^{\text {st }}$ April until May $3^{\text {rd }} 2020$. Ethical approval was obtained from of the Hospital Universitário Pedro Ernesto (HUPE), Universidade do Estado do Rio de Janeiro (UERJ), Plataforma Brasil with the number CAAE 30649620.1.0000.5259.

\section{Sample}

Brazilian population over 18 years old was invited to participate of this study. The responders who agreed to participate, after an explanation of the consent form in the beginning of the survey, with $\geq 18$ years old, were included. At any time, the responder could give up concluding the survey without any penalty or constraints. Brazilians were divided according to the macro-region where they lived during the survey application. Survey. The questionnaire PEFCOVID19 was created to assess the levels of physical exercise and psychological impact of general population before and during the social isolation due to the COVID-19 pandemic. The psychometric properties of this instrument were previously described [14], and it reports the validity indexes and the test-retest reliability and feasibility, being considered a valid and reliable instrument.

The PEF-COVID19 was divided into four sections,

(I) Subject's characterization with demographic, anthropometric and health status questions;

(II) Physical exercise performed or not, pain, anxiety and stress before COVID-19;

(III) Confinement situation update;

(IV) Physical exercise performed or not, pain, anxiety and stress during COVID-19 [14].

\section{Data Collection}

The questionnaire was distributed using social and network media (Whatsapp, Facebook, Messenger, Linkedin), and email inviting people in general to participate and asking them to share with family and friends through the link: https://docs.google.com/ forms/d/e/1FAIpQLScgnHqfHH5NjLQHv6sLnbtz38eg1hBTu3U y3jxgIV0Ou7-_gw/viewform?usp=sf_link. Participant responses were secured where the data was recorded, scaled and scored in electronic sheets by custom Excel formulas for later statistical analysis.

\section{Statistical Analysis}

All data were exported to an Excel sheet. Nominal data were coded for statistical purposes. The statistical analyses were performed using IBM SPSS Statistics for Windows (version 21.0., IBM Corp., Armonk, NY, USA). Descriptive statistical analyses (n, $\%$ ) were performed and the independent chi-square test. Post hoc analyses were performed on multiple category data with the Bonferroni correction. Comparisons between the groups (Brazil and mains Brazilian macro-regions) for the categorical variables of pain, stress, anxiety, sex, smoking habits, were made using chi squared analysis. Age distributions, mass, height, body mass index, years smoking, between Brazil and mains macro-regions, were compared using an independent $t$ test. 


\section{Results}

A total of 1,977 participants filled the survey. Prior to data analysis, 129 answers were excluded (6.5\%) of the initial respondents because they were from other countries than Brazil or with age below 18 years-old, leaving a total of 1,848 questionnaires to be considered in the current study. Brazil has five different macroregions. Table 1 shows different Brazilian regions population, the number of respondents and the respondents' percentage per millions of people from each region. South (S), Southeast (SE) and Northeast (NE) are the regions with the higher percentages of respondents per million of inhabitants. In general, the survey reached $8.8 \%$ of respondents per million of person considering the Brazilian population. As expected, Midwest and North regions, with the bigger territories and smaller population, had a little number of answers and for that reason these answers were analyzed in the Tables with the Brazilian population as a whole.

Table 1: Number of respondents per million from the different Brazilian regions.

\begin{tabular}{|c|c|c|c|c|}
\hline Macro Regions & $\%$ of Brazil area & Inhabitants* & Number of respondents & $\begin{array}{c}\text { Respondents per million } \\
\text { of person }\end{array}$ \\
\hline South & 6.8 & $29,975,984$ & 378 & 12.6 \\
\hline Southeast & 10.9 & $88,371,433$ & 964 & 10.9 \\
\hline Northeast & 18.2 & $57,071,654$ & 431 & 7.5 \\
\hline Midwest & 18.8 & $16,297,074$ & 52 & 3.2 \\
\hline North & 45.2 & $18,430,980$ & 20 & 1.1 \\
\hline
\end{tabular}

Note: *DATASUS (http:/ / tabnet.datasus.gov.br/cgi/tabcgi.exe?ibge/cnv/ poptuf.def);

\section{Sociodemographic Characteristics and Sample Health Condition}

The majority of the participants were young-adults (53.3\%), followed by adults (23.4\%), young (14.7\%) and elderly (8.6\%). Comparing Brazil with the mains macro-regions, the age distribution and sex was similar $(\mathrm{P}>0.05)$. Between the respondents, $70 \%$ was female, $29.8 \%$ male and $0.2 \%$ did not want to declare. The mean \pm SD age was $39.5 \pm 13.3$ years, body mass $71.4 \pm 26.3 \mathrm{~kg}$, height $1.7 \pm 0.4 \mathrm{~m}$ and Body Mass Index (BMI) $25.4 \pm 7.8 \mathrm{~kg} \cdot \mathrm{m}^{-2}$. The $\mathrm{S}$ and $\mathrm{NE}$ regions presented less mean body mass and consequently less BMI compared to Brazil in general $(24.5 \pm 4.3$ and $24.8 \pm 4.1 \mathrm{~kg} . \mathrm{m}$ 2 , respectively), $(\mathrm{P}<0.05)$. Considering the marital status of the sample, $50.8 \%$ was married, $38.3 \%$ was single and $9.4 \%$ and $1.5 \%$ was, respectively divorced and widowed. The majority of the sample worked in the public (30.1\%) or private sectors $(28.2 \%)$. Students were $15.5 \%$, retired $7 \%$ and unemployed $6.5 \%$. The registered selfrelated current health condition showed that $56 \%$ of the sample had any disease, $14 \%$ respiratory diseases followed by musculoskeletal $(10.7 \%)$, cardiac and related conditions (10.2\%), mental health $(8.4 \%)$ and $0.2 \%$ neurological diseases. Smoking habits occur in $4.1 \%$ of the total sample. Considering the sociodemographic and current health condition variables, no differences were found between Brazil and mains macro-regions $(\mathrm{P}>0.05)$.

\section{Social Isolation Status}

Most of the individuals were in social isolation $(\sim 80 \%)$ at the time of the survey application and the ones that were not in social isolation $(\sim 15 \%)$ were not released from their jobs. Few respondents $(1.5 \%)$ do not believe in the importance of social isolation.

\section{Pain and Psychological Impact}

The level of pain and psychological impact of the sample before and during the COVID-19 pandemic are presented on Table 2. Considering the pain before and during the COVID-19 pandemic for the Brazilian general population, the independent chi-square test showed that the COVID-19 pandemic influenced the pain perception $\left[\mathrm{X}^{2}(1)=33.2 ; \mathrm{P}<0.0001\right]$; the odds ratio for COVID-19 before/during is 1.477 . When analyzing the different regions of Brazil, SE $\left[\mathrm{X}^{2}(1)=23.951 ; \mathrm{P}<0.0001\right]$ e $\mathrm{NE}\left[\mathrm{X}^{2}(1)=8.779 ; \mathrm{P}<0.01\right]$ regions showed the same pattern, however, the $\mathrm{S}$ region accepted the null hypothesis $\left[\mathrm{X}^{2}(1)=1.384 ; \mathrm{P}>0.05\right]$. To verify the body regions with pain before and during the COVID-19 pandemic for the Brazilian general population, the independent chi-square test showed that the COVID-19 pandemic influenced the body regions with pain $\left[\mathrm{X}^{2}(4)=15.215 ; \mathrm{P}<0.01\right]$; after the Bonferroni post hoc correction only the pain in head and neck regions were influenced by the pandemic, with increase in pain $(\mathrm{P}<0.001)$. 
Table 2: Level of pain and mental health impact of the sample from the Brazilian general population ( $\mathrm{n}=1,848)$, aged from 18 years old and divided by the 3 mains Brazilian macro-regions, South (S) $n=378$, Southeast (SE) $n=964$ and Northeast (NE) $n=431$, before and during the COVID-19 pandemic. Values are presented as percentage (\%).

\begin{tabular}{|c|c|c|c|c|c|c|c|c|}
\hline & \multicolumn{4}{|c|}{ Pain, Anxiety and Stress before COVID-19 } & \multicolumn{4}{|c|}{ Pain, Anxiety and Stress during COVID-19 } \\
\hline & Brazil & S & SE & NE & Brazil & S & SE & NE \\
\hline \multicolumn{9}{|c|}{ Pai006E } \\
\hline Yes/No & $34.6 / 65.4$ & $41.9 / 58.1$ & $33.1 / 66.9$ & $32.3 / 67.7$ & $44 * / 56$ & $46.4 / 53.6$ & $44 * / 56$ & $42.1 / 57.9$ \\
\hline \multicolumn{9}{|c|}{ Pain BR $^{x}$} \\
\hline Head\&neck & 11.9 & 11.7 & 11.3 & 10.8 & $18.7^{*}$ & 17.4 & $20.4^{*}$ & 15.2 \\
\hline Upper limbs & 13.2 & 12.9 & 14 & 11.5 & 14.4 & 14 & 14.5 & 14.1 \\
\hline Back & 45.8 & 46 & 45.1 & 48.6 & 41.7 & 39.9 & 40.3 & 47.3 \\
\hline Hip & 7.7 & 11 & 5.8 & 7.4 & 6.1 & 7.3 & 4.9 & 5.4 \\
\hline Lower limbs & 21.5 & 18.4 & 23.8 & 21.6 & 19.1 & 21.3 & 19.9 & 17.9 \\
\hline \multicolumn{9}{|c|}{ Level of pain ${ }^{\infty}$} \\
\hline $0-3$ & 33.6 & 33.1 & 33.6 & 32.7 & 28.7 & 27.8 & 29.9 & 24.9 \\
\hline $4-7$ & 55.6 & 56.4 & 55.5 & 57.7 & 55.1 & 58 & 52.5 & 58.4 \\
\hline $8-10$ & 10.8 & 10.5 & 10.9 & 9.6 & $16.2^{*}$ & 14.2 & $17.6^{*}$ & $16.8^{*}$ \\
\hline \multicolumn{9}{|c|}{ Level of Anxiety } \\
\hline $0-3$ & 42.8 & 41.4 & 42.8 & 43.4 & $21.7^{*}$ & $18.5^{*}$ & $21.2^{*}$ & $23.6^{*}$ \\
\hline $4-7$ & 47.1 & 50.4 & 47 & 46.8 & 44.4 & 47.7 & 44 & 43.6 \\
\hline $8-10$ & 9.8 & $8.2^{*}$ & 10.3 & 9.8 & $34.1^{*}$ & $33.9 *$ & $34.7^{*}$ & $33^{*}$ \\
\hline \multicolumn{9}{|c|}{ Level of Stress } \\
\hline $0-3$ & 34.1 & 35.8 & 32.1 & 35.8 & $26.6^{*}$ & 26.9 & $26^{*}$ & $26.8^{*}$ \\
\hline $4-7$ & 51.8 & 49.4 & 53.3 & 52.1 & $43.1^{*}$ & 41.6 & $44.6^{*}$ & 43.3 \\
\hline $8-10$ & 13.9 & 14.9 & 14.3 & 12.1 & $29.7^{*}$ & $31.4^{*}$ & $29.3^{*}$ & $30^{*}$ \\
\hline
\end{tabular}

Note: PEx, Physical Exercise; BR, body regions; ${ }^{\circledR}$ percentages within the pain cases; ${ }^{*}$ Chi-square statistical significance with Bonferroni post hoc correction, comparing before and after the COVID-19 pandemic.

When analyzing the different regions of Brazil, only the SE $\left[\mathrm{X}^{2}(4)=11.956 ; \mathrm{P}<0.001\right]$ region showed the same pattern for an increase in head and neck pain during the pandemic; however, the $S$ and NE regions accepted the null hypothesis $\left[\mathrm{X}^{2}(4)=4.434\right.$; $\mathrm{P}>0.05]$ and $\left[\mathrm{X}^{2}(4)=2.763 ; \mathrm{P}>0.05\right]$, respectively. The level of selfrelated pain analysis before and during the COVID-19 pandemic for the Brazilian general population, the independent chi-square test showed that the COVID-19 pandemic influenced the level of pain $\left[\mathrm{X}^{2}(2)=11.635 ; \mathrm{P}<0.01\right]$; after the Bonferroni post hoc correction the pain in the highest levels (8-10) were influenced by the pandemic, with increase in pain $(\mathrm{p}=0.001)$. When analyzing the different regions of Brazil, only the SE $[\mathrm{X} 2(4)=7.357 ; \mathrm{P}<0.05]$ region showed the same pattern for the highest levels of pain during the pandemic after the post hoc $(\mathrm{P}<0.01)$; however, the $\mathrm{S}$ and $N E$ regions accepted the null hypothesis $\left[\mathrm{X}^{2}(2)=1.823 ; \mathrm{P}>0.05\right]$ and $\left[X^{2}(2)=5.146 ; P>0.05\right]$, respectively.

The level of self-related anxiety before and during the COVID-19 pandemic for the Brazilian general population showed with the independent chi-square test that the COVID-19 pandemic influenced the level of anxiety $\left[\mathrm{X}^{2}(2)=376.904\right.$; $\left.\mathrm{P}<0.0001\right]$; after the Bonferroni post hoc correction the anxiety in the highest levels (8-10) were influenced by the pandemic, with increase in anxiety $(\mathrm{P}<0.01)$. When analyzing the different regions of Brazil, the $\mathrm{S}$ region $\left[\mathrm{X}^{2}(2)=92.292 ; \mathrm{P}<0.0001\right]$ after the Bonferroni post hoc correction the anxiety in the smallest levels (0-3) decreased $(\mathrm{P}<0.0001)$ probably due to the increase of the highest levels of anxiety (8-10), $(\mathrm{P}<0.0001)$; the $\mathrm{SE}\left[\mathrm{X}^{2}(2)=197.898 ; \mathrm{P}<0.0001\right]$ and $\mathrm{NE}\left[\mathrm{X}^{2}(2)=80.534 ; \mathrm{P}<0.0001\right]$ regions showed the same pattern for the smallest and highest levels of anxiety during the pandemic after the post hoc $(\mathrm{p}<0.0001)$.

To verify the stress before and during the COVID-19 pandemic for the Brazilian general population, the independent chi-square test showed that the COVID-19 pandemic influenced the stress $\left[\mathrm{X}^{2}(2)=\right.$ 137.857; $\mathrm{P}<0.0001]$; after the Bonferroni post hoc correction all self-related stress levels were influenced by the pandemic, with an decrease in the low (0-3) and moderate (4-7) levels and an increase in the highest stress levels $(\mathrm{P}<0.0001)$. When analyzing the different regions of Brazil, the $\mathrm{S}$ region $\left[\mathrm{X}^{2}(2)=29.617 ; \mathrm{P}<0.0001\right]$ after the Bonferroni post hoc correction the anxiety in the highest levels of stress $(8-10)$ increased during the pandemic $(\mathrm{P}<0.0001)$; the SE 
$\left[X^{2}(2)=62.693 ; P<0.0001\right]$ after the post hoc for all stress levels $(\mathrm{P}<0.01)$; and $\mathrm{NE}\left[\mathrm{X}^{2}(2)=41.933 ; \mathrm{P}<0.0001\right]$ regions showed an increase for the highest levels of stress $(\mathrm{P}<0.0001)$ and a decrease for the smallest stress levels $(\mathrm{P}<0.01)$ during the pandemic.

\section{Discussion}

To the best of our knowledge, this is the first study to evaluate the level of pain and psychological impact as stress and anxiety together in Brazilian mains macro-regions during the COVID-19 outbreak. Our hypotheses were confirmed, and COVID-19 lockdown contributed negatively to increase the levels of selfrelated pain, anxiety and stress. It was observed that the majority of the respondents were following the social isolation during the first wave of the pandemic and government restrictions (about 80\%) considering that in February 3rd the epidemic was declared a Public Health Emergency of National Concern [15] following the notifications of the disease spread and deaths in all continents [16]. The decrease of exercise and physical activity during the pandemic and SI can also generate mental health impacts, as stress or anxiety [17] that many will experience in the face of the feeling of fear [18] (fear of being sick or dying, possible loss of family and friends, economic impact) and isolation from common social life $[19,20]$. Moreover, this survey shows alarming results considering the level increase of anxiety and stress, which the highest levels (810 ) in a scale with a maximum of 10 points increased significantly comparing before and during the pandemic for Brazil.

A recent study [21] investigated the fear of COVID-19, stress and anxiety in undergraduate students from Ecuador; they observed the complex relationships between fear, stress, and anxiety in the development of depression symptoms and how they can be taken into account in programs aimed to prevent and alleviate the mental health disorders. Two other studies presented also the effects of the pandemic on mental health for general Brazilian population $[6,22]$ and in both studies anxiety, depression and stress scores were higher during the pandemic, and mainly the ones that were not physically active [22]. Also, the self-related pain level increased significantly mainly in the head and neck regions for Brazilians in general and SE macro-region inhabitants. Inappropriate posture watching television, using computers $[23,24]$ and smartphones [25] or psychosocial stressors [20,26] might be the reason for the pain increase in such body regions. Furthermore, in a review [27], the authors verified strong consistent evidence for the relationship between both psychological distress, and time spent using screens for leisure and depressive symptomatology.

Moderate evidence supported the relationship between low self-esteem and screen use. Poorer mental health status was found among adolescents using screen time more than 2-3h per day, and gender differences exist. Corroborating with our findings, considering that SI can favor chronic stress and pain, Majumdar et al, 2020 [28] reported that the chronic stress of living through a pandemic led to a host of physical symptoms, like headaches, insomnia, digestive problems, hormonal imbalances, and fatigue. The southeastern region is the most populated and industrialized region of Brazil and probably suffered most an economic imbalance due to the pandemic. Since the outbreak of the novel coronavirus was first detected, the world has been challenged since the health systems were overloaded in large large-scale, economy income decreased and market volatility, unemployment, mental health issues and lifestyle changes with sedentary behavior increase, leading, perhaps, to an increase in chronic diseases.

Professions were also reinvented as populations never expected, mainly the education and heath area professions. Moreover, as it was pointed out by Zieff, et al. [29], targeting sedentary behavior is a simple strategy that may help counter physical and mental health concerns associated with COVID-19-related social restrictions. During the SI, Brazilians in general decreased the self-related levels of physical exercise and changed the exercise habits [5]. Of course, traditional strategies such as achieving optimal exercise and physical activity levels are also important and should be recommended. However, even under normal circumstances, the difficulty in promoting lasting exercise habits at multiple levels (e.g. individual, environment, policy) are well documented [4,5,29,30], and chances of maintaining or improving these factors is now even lower. Thus, relative to other lifestyle behaviors - sedentary behavior may be more amenable to change.

Moreover, reducing sedentary behavior may be less susceptible to influence from factors associated with health disparities such as age, race, and socio-economic status compared to exercise or physical activity. Sedentary behavior is a feasible health strategy that should be targeted during COVID-19. The strengths and the applications of the findings described in this study and considering the return to the normal life is still unexpected, the results from the current study can help to create measures to decrease mental health disturbances, facing the fear of the unknown. Moreover, as a perspective, it is expected that with the comparison of some parameters before and during the outbreak, the results can aid in the definition of policies to help the Brazilian population, in general, and in specific regions, due to the COVID-19 period post-pandemic. As a limitation, the number of respondents was different in the various regions that were investigated. Moreover, in two regions, North and Midwest, the number of respondents was reduced.

Due to the unknown home-quarantine in each region of the country, a specific adaptation of the questionnaire was not possible to be done. In general, the Brazilian regions have specific characteristics, as nutrition, political approaches, and local costumes. Also, self-reported instruments can induce bias. The 
findings obtained with the PEF-COVID19 showed, in general, that the Brazilian general population was affected by the pandemic considering the increased levels of self-related pain, stress and anxiety. SE macro-region is the economic center of Brazil presented a significant increase in the levels of self-related pain compared to the others mains macro-regions; the higher levels (8-10) of stress and anxiety increased significantly in all studied macroregions, with similar results. These results will be valuable to the establishment of actions to aid the population of Brazil to minimize, with different approaches, the undesirable commitment due the social distancing related to the COVID-19.

\section{Acknowledgement}

We acknowledge the Brazilians that contributed filling this survey.

\section{Conflict of Interest}

The authors declared no potential conflicts of interest.

\section{Funding}

This study was financed by the Coordenação de Aperfeiçoamento de Pessoal de Nível Superior (CAPES) - finance code 001 and the Brazilian National Council for Scientific and Technological Development (CNPq).

\section{References}

1. Melo Oliveira ME, Sá Caputo D, Bachur JA, Paineiras-Domingos LL, Sonza A, et al. (2020) Reported quality of life in countries with cases of COVID19: a systematic review. Expert Rev Respir Med, p. 1-8.

2. Lau H, Khosrawipour V, Kocbach P, Schubert J, Bania J, et al. (2020) The positive impact of lockdown in Wuhan on containing the COVID-19 outbreak in China. J Travel Med 1: 1-14.

3. Narici M, De Vito G, Franchi M, Paoli A, Moro T, et al. (2020) Impact of sedentarism due to the COVID-19 home confinement on neuromuscular, cardiovascular and metabolic health: Physiological and pathophysiological implications and recommendations for physical and nutritional countermeasures. Eur J Sport Sci 0: 1-22.

4. Da Cunha de Sá-Caputo D, Taiar R, Seixas A, Sanudo B, Anelise Sonza, et al. (2020) A Proposal of Physical Performance Tests Adapted as Home Workout Options during the COVID-19 Pandemic. Appl Sci 10: 4755.

5. Sonza A, Sá-Caputo D da C de, Bachur JA, Araújo M das GR de, Karen Valadares Trippo, et al. (2020) Brazil before and during COVID-19 pandemic: Impact on the practice and habits of physical exercise. Acta Biomed Parma. in press, p. 1-9.

6. Sonza A, Da Cunha de Sá Caputo D, Sartorio A, Tamini S, Seixas A, et al. (2021) COVID-19 Lockdown and the Behavior Change on Physical Exercise, Pain and Psychological Well-Being: An International Multicentric Study. Int J Environ Res Public Health 18: 1-20.

7. DeSantana JM (2020) What about patients with pain during and after the COVID-19 pandemic? Brazilian J Pain 3(3): 292-393.

8. AMMAR A, Brach M, Trabelsi K, Chtourou H, Boukhris O, et al. (2020) Effects of COVID-19 home confinement on physical activity and eating behaviour Preliminary results of the ECLB-COVID19 international online-survey. medRxiv.
9. Moghanibashi Mansourieh A (2020) Assessing the anxiety level of Iranian general population during COVID-19 outbreak. Asian J Psychiatr 51: 102076.

10. Karayannis NV, Baumann I, Sturgeon JA, Melloh M, Mackey SC (2019) The Impact of Social Isolation on Pain Interference: A Longitudinal Study. Ann Behav Med 53(1): 65-74.

11. Oliveira VC, Ferreira ML, Morso L, Albert HB, Refshauge KM (2015) Patients' perceived level of social isolation affects the prognosis of low back pain. Eur J Pain 19(4): 538-545.

12. Eisenberger NI (2012) The pain of social disconnection: examining the shared neural underpinnings of physical and social pain. Nat Rev Neurosci 13(6): 421-434.

13. Cole SW, Hawkley LC, Arevalo JM, Sung CY, Rose RM, et al. (2007) Social regulation of gene expression in human leukocytes. Genome Biol 8(9): R189.

14. SáCaputo D da C de, Sonza A, Bachur JA, Bernardo Filho M (2020) Development, validation and reliability of a questionnaire to evaluate changes on the level of physical exercises and psychological impact due to COVID-19 pandemic social distancing. Acta Biomed 91(3): e2020004.

15. MS MDS. Declara Emergência em Saúde Pública de importância Nacional (ESPIN) em decorrência da Infecção Humana pelo novo Coronavírus.

16. Scafetta N (2020) Distribution of the SARS-CoV-2 Pandemic and Its Monthly Forecast Based on Seasonal Climate Patterns. Int J Environ Res Public Health 17: 3493.

17. Hall G, Laddu DR, Phillips SA, Lavie CJ, Arena R (2020) A tale of two pandemics: How will COVID-19 and global trends in physical inactivity and sedentary behavior affect one another? Prog Cardiovasc Dis 64: 108-110.

18. Mertens G, Gerritsen L, Duijndam S, Salemink E, Engelhard IM (2020) Fear of the coronavirus (COVID-19): Predictors in an online study conducted in March 2020. J Anxiety Disord 74: 102258.

19. Dubey S, Biswas P, Ghosh R, Chatterjee S, Dubey MJ, et al. (2020) Psychosocial impact of COVID-19. Diabetes Metab Syndr Clin Res Rev 14(5): 779-788.

20. Sep MSC, Steenmeijer A, Kennis M (2019) The relation between anxious personality traits and fear generalization in healthy subjects: A systematic review and meta-analysis. Neurosci Biobehav Rev 107: 320328.

21. Rodríguez Hidalgo AJ, Pantaleón Y, Dios I, Falla D (2020) Fear of COVID-19, Stress, and Anxiety in University Undergraduate Students: A Predictive Model for Depression. Front Psychol.

22. Silva LRB, Seguro CS, De Oliveira CGA, Santos POS, De Oliveira JCM, et al. (2020) Physical Inactivity Is Associated with Increased Levels of Anxiety, Depression, and Stress in Brazilians During the COVID-19 Pandemic: A Cross-Sectional Study. Front Psychiatry 11.

23. Barbieri DF, Srinivasan D, Mathiassen SE, Oliveira AB (2019) Variation in upper extremity, neck and trunk postures when performing computer work at a sit-stand station. Appl Ergon 75: 120-128.

24. Palmer K, Ciccarelli M, Falkmer T, Parsons R (2014) Associations between exposure to Information and Communication Technology (ICT) and reported discomfort among adolescents. Work 48(2): 165-173.

25. Iyengar K, Upadhyaya GK, Vaishya R, Jain V (2020) COVID-19 and applications of smartphone technology in the current pandemic. Diabetes Metab Syndr Clin Res Rev 14(5): 733-737.

26. Clauw DJ, Häuser W, Cohen SP, Fitzcharles MA (2020) Considering the potential for an increase in chronic pain following the COVID-19 pandemic 161(8): 1694-1697. 
27. Hoare E, Milton K, Foster C, Allender S (2016) The associations between sedentary behaviour and mental health among adolescents: a systematic review. Int J Behav Nutr Phys Act 13: 108.

28. Majumdar P, Biswas A, Sahu S (2020) COVID-19 pandemic and lockdown: cause of sleep disruption, depression, somatic pain, and increased screen exposure of office workers and students of India. Chronobiol Int 37(8): 1191-200.

\section{ISSN: 2574-1241}

DOI: 10.26717/BJSTR.2021.37.006003

Anelise Sonza. Biomed J Sci \& Tech Res

(c) (P) This work is licensed under Creative

Submission Link: https://biomedres.us/submit-manuscript.php
29. Zieff G, Bates LC, Kerr ZY, Moore JB, Hanson ED, et al. (2020) Targeting sedentary behavior as a feasible health strategy during COVID-19. Transl Behav Med 11(3): 826-831.

30. Ricci F, Izzicupo P, Moscucci F, Sciomer S, Maffei S, et al. (2020) Recommendations for Physical Inactivity and Sedentary Behavior During the Coronavirus Disease (COVID-19) Pandemic. Front Public Heal, p. 8-11.

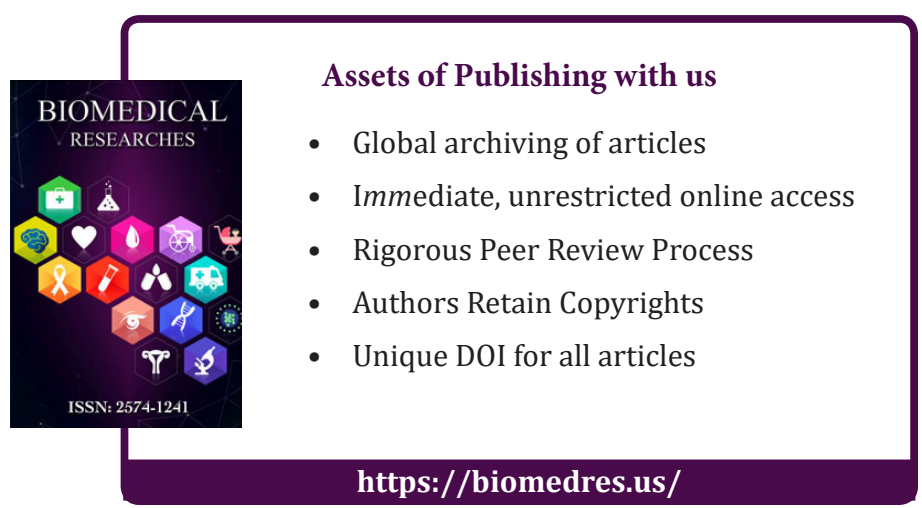

